\title{
Utility-Based Early Modulation of Processing Distracting Stimulus Information
}

\author{
Mike Wendt, Aquiles Luna-Rodriguez, and Thomas Jacobsen \\ Helmut-Schmidt-University/University of the Federal Armed Forces Hamburg, Experimental Psychology Unit, 22043 Hamburg, Germany
}

\begin{abstract}
Humans are selective information processors who efficiently prevent goal-inappropriate stimulus information to gain control over their actions. Nonetheless, stimuli, which are both unnecessary for solving a current task and liable to cue an incorrect response (i.e., "distractors"), frequently modulate task performance, even when consistently paired with a physical feature that makes them easily discernible from target stimuli. Current models of cognitive control assume adjustment of the processing of distractor information based on the overall distractor utility (e.g., predictive value regarding the appropriate response, likelihood to elicit conflict with target processing). Although studies on distractor interference have supported the notion of utility-based processing adjustment, previous evidence is inconclusive regarding the specificity of this adjustment for distractor information and the stage(s) of processing affected. To assess the processing of distractors during sensory-perceptual phases we applied EEG recording in a stimulus identification task, involving successive distractor-target presentation, and manipulated the overall distractor utility. Behavioral measures replicated previously found utility modulations of distractor interference. Crucially, distractor-evoked visual potentials (i.e., posterior N1) were more pronounced in high-utility than low-utility conditions. This effect generalized to distractors unrelated to the utility manipulation, providing evidence for item-unspecific adjustment of early distractor processing to the experienced utility of distractor information.
\end{abstract}

Key words: conflict adaptation; contingency learning; early selection; visual attention

\section{Introduction}

A hallmark of human behavior is the ability to apply arbitrary stimulus-response translation rules to a particular (target) component of the stimulus environment, making this stimulus information dominate action selection over the information provided by additional (distractor) stimuli. Nevertheless distractor processing beyond a purely sensory level is frequently evidenced in performance differences contingent on the relationship of target and distractor stimuli. Specifically, responding tends to be faster and more accurate when a distractor is associated with the same response as the target (henceforth congruent) than when distractor and target are associated with different responses (henceforth incongruent), even if targets and distractors are easily discernible by distinct physical features (Stroop, 1935; Eriksen and Eriksen, 1974).

Rather than considering the processing of distractors mere failures of selection, current models of cognitive control frequently assume that the "weight" of distractor information is

\footnotetext{
Received Feb. 24, 2014; revised Sept. 26, 2014; accepted 0ct. 6, 2014.

Author contributions: M.W., A.L.-R., and T.J. designed research; M.W., A.L.-R., and T.J. performed research; M.W., A.L.-R., and T.J. analyzed data; M.W., A.L.-R., and T.J. wrote the paper.

This research was funded by a grant from the German Research Foundation (Deutsche Forschungsgemeinschaft; WE 4105/1-2 to M.W.). We are grateful to Jana Burock, Svantje Kähler, Jonathan Manske, and Falco Walther for their assistance with collecting the data.

The authors declare no competing financial interests.

Correspondence should be addressed to Mike Wendt, Helmut-Schmidt-University/University of the Federal Armed Forces Hamburg, Experimental Psychology Unit, Holstenhofweg 85, 22043 Hamburg, Germany. E-mail: mike.wendt@hsu-hh.de.

DOI:10.1523/JNEUROSCI.0754-14.2014

Copyright $\odot 2014$ the authors $\quad 0270-6474 / 14 / 3416720-06 \$ 15.00 / 0$
}

strategically adjusted to the experienced utility of this information (Logan and Zbrodoff, 1979; Gratton et al., 1992; Botvinick et al., 2001; Melara and Algom, 2003). The overall distractor utility can be manipulated by varying the ratio of congruency levels (e.g., making distractors, on average, more disruptive to performance by increasing the proportion of incongruent trials) and/or the contingencies of distractors and targets/responses (giving the distractor more or less predictive value). Such manipulations yielded support for the notion of strategic processing adjustment by demonstrating a larger congruency effect in high-utility than in low-utility conditions (proportion congruency effect; Gratton et al., 1992; Crump and Milliken, 2009).

Previous research left two theoretically relevant questions unanswered, however. First, because behavioral as well as physiological measures used so far are likely affected by both distractor and target information, adjustment effects cannot be considered direct evidence for variations in distractor processing (Egner and Hirsch, 2005). Second, it has not been determined what stages of processing are influenced by distractor utility manipulations; previous findings are consistent with alterations in stimulus encoding, "post-perceptual" phases of response selection, or both (Wendt et al., 2012).

EEG studies demonstrated attentional modulation of stimulus processing in the form of larger brain potentials evoked by (otherwise equivalent) stimuli designated as targets than as distractors (Hillyard and Anllo-Vento, 1998; Hillyard et al., 1998). Unlike target stimuli, distractors in choice tasks (1) provide, at best, unreliable and frequently misleading response cues; (2) are not associated with an instruction to be "attended" or used for task performance; and (3) are necessarily presented together with 
additional information that reliably indicates the required response (i.e., the target). To investigate utility-related adjustment of processing such information during early stages, we manipulated distractor utility in a successive distractor-target presentation procedure (Fig. 1a). This enabled us to assess distractor-evoked ERPs before target processing while keeping "attentional instructions" and reliability of additional stimulus information constant. To determine the generality of utility-related modulations, we added neutral distractors (i.e., stimuli that did not afford the instructed task) in a second experiment.

\section{Materials and Methods}

\section{Experiment 1}

Participants. Sixteen neurologically healthy students ( 1 female, 15 male, mean age 24.4 years, range 23-27 years) of the Helmut-Schmidt-University/University of the Federal Armed Forces Hamburg gave informed consent to participate in the study in exchange for partial fulfillment of course requirements. All had normal or corrected-to-normal vision according to self-report, and were naive with respect to the purpose of the experiment.

Apparatus and stimuli. The experiment was run on a standard PC using MATLAB R2010a and Psychtoolbox 3 software. A second computer running BrainVision Recorder 1.20 (Brain Products EEG/fMRI Hardware, RRID: nlx 155587) stored EEG data, as well as triggered marking timing and identity of each stimulus and response administered by the first computer. The experiment was run inside an acoustically and electromagnetically shielded room. Stimuli were presented on a 24 inch LCD monitor, viewed at a distance of $\sim 1.5 \mathrm{~m}$. The letters $\mathrm{E}, \mathrm{I}, \mathrm{O}$ and $\mathrm{U}$, displayed in black color in the center of the screen on a white rectangle, covering slightly more than their vertical and horizontal extensions, subtending visual angles ranging from 1.7 to $1.8^{\circ}$ vertically and 1.1 to $1.6^{\circ}$ horizontally, acted as target and distractor stimuli. The rest of the screen showed a dark gray background.

Procedure. Each trial involved the consecutive presentation of a distractor letter and a target letter each shown for $250 \mathrm{~ms}$ and separated by a 100 ms blank screen (Temporal Flanker Task; Hazeltine et al., 2011). Participants were instructed to respond exclusively to the second letter by pressing one of four keys on a purpose-built keyboard (response time resolution $<1 \mathrm{~ms}$ ), using the middle and index fingers of both hands. The inner two response keys (which were operated by the index fingers) were slightly nearer to the participant than the two outer keys. The response to each letter was mapped to the keyboard from left to right in alphabetical order. After each correct response, the screen remained blank for $1 \mathrm{~s}$ before the next trial started with the presentation of the distractor. After an incorrect response a message indicating the correct response was shown for $1 \mathrm{~s}$ followed by a $1 \mathrm{~s}$ blank screen. Blocks of 99 trials were presented, starting with a practice block and followed by 12 experimental blocks. Feedback concerning mean reaction time (RT) and error proportion was given after each block. Between blocks, participants were allowed to rest for some time. During one half of the experimental session (either blocks $1-6$ or blocks $7-12$, order balanced among participants) both distractor and target were chosen at random on each trial, resulting in probabilities of 0.25 and 0.75 for congruent and incongruent trials, respectively (i.e., low-utility condition). During the other half of the experimental session, distractors and targets were chosen randomly with the only constraint that congruent and incongruent trials were associated with probabilities of 0.75 and 0.25 , respectively (i.e., high-utility condition). The participants were not explicitly informed about the different probabilities.

EEG recording. Twenty-four $\mathrm{Ag} / \mathrm{AgCl}$ electrodes were mounted in an elastic cap and placed according to the international 10-20 system. The reference electrode was attached to the subject's nose tip and ground electrode to AFz. Horizontal and vertical electro-oculograms were recorded using bipolar montages. Another two electrodes were mounted on the mastoids for off-line referencing, for a total of 32 electrodes. All channels were amplified (with a low cutoff of $15 \mathrm{~s}$ and a high cutoff of 249 $\mathrm{Hz}$ ) and recorded at a $500 \mathrm{~Hz}$ sampling rate. After each block, EEG data were stored and the recorder performed a new DC reset. Impedance of all electrodes was kept below $10 \mathrm{k} \Omega$.

Statistical analyses. The EEG data were imported and analyzed using EEProbe 3.3.122 software (ANT Neuro, RRID: nlx 155750) in a Linux environment. Data from the first three trials of each block and from trials immediately following an incorrect response were excluded from all analyses. For the EEG analyses and the RT analyses, all data from trials associated with an incorrect response also were excluded. To control for low-level (trial-to-trial) priming all data from trials in which the distractor character occurred in the preceding trial (either as target, as distractor, or as both) were excluded from all analyses. Because the EEG analyses focused on the interval preceding the target, we did not add target repetition as an exclusion criterion for these analyses. However, for the analyses of the RT and response accuracy measures all data from trials in which the target character occurred in the preceding trial (either as target, as distractor, or as both) also were excluded. Artifact rejection was performed using a criterion of $\pm 120 \mu \mathrm{V}$. Due to the cap fitting loosely in some subjects, only the 18 top electrodes (i.e., Fp1, Fp2, F3, Fz, F4, Fc1, $\mathrm{Fcz}, \mathrm{Fc} 2, \mathrm{C} 3, \mathrm{Cz}, \mathrm{C} 4, \mathrm{Cp} 1, \mathrm{Cp} 2, \mathrm{P} 3, \mathrm{Pz}, \mathrm{P} 4, \mathrm{O} 1$, and $\mathrm{O} 2$ ) and the electrooculograms were used for trial rejection. ERPs were averaged for epochs of $450 \mathrm{~ms}$, preceding target onset. This epoch includes a $100 \mathrm{~ms}$ baseline before the onset of the distractor, presentation of the distractor $(-350 \mathrm{~ms}$ to $-100 \mathrm{~ms}$ ), and a blank screen of $100 \mathrm{~ms}$ duration. On average, data from $318(S D=85)$ and $257(S D=68)$ epochs per participant, for high-utility blocks and low-utility blocks, respectively, were used for further analyses. The difference between blocks was mainly due to a larger probability for a given distractor to have occurred on the preceding trial-and thus data from the trial were excluded from the analyses-when the majority of trials involved two different characters (i.e., incongruent).

Statistical analyses were performed on unfiltered data, but figures show ERPs of $20 \mathrm{~Hz}$ low-pass filtered data. Statistics for the difference between high-utility and low-utility conditions used the mean amplitude values for $20 \mathrm{~ms}$ windows centered on the grand-average peak of $\mathrm{N} 1$. The peak latency of $\mathrm{N} 1$ for both utility conditions was at $186 \mathrm{~ms}$ after distractor onset. To compare N1 amplitudes in high-utility and low-utility blocks, the mean amplitude values of electrodes F3, F4, C3, C4, P7, P8, $\mathrm{O} 1$, and $\mathrm{O} 2$ were subjected to an ANOVA with repeated measures on the factors utility condition (2), anterior-posterior electrode site (4), and left-right electrode site (2).

To assess the potency of the distractors to activate their associate responses in high-utility versus low-utility conditions we calculated the lateralized readiness potential (LRP) in high-utility versus low-utility conditions. To this end, C3 and C4 signals were recalculated for each trial, separately for low-utility and high-utility blocks, by subtracting signals from the electrode ipsilateral to the hand associated with the distractor-related response from signals from the electrode contralateral to the hand associated with the distractor-related response, averaged across the $100 \mathrm{~ms}$ blank screen interval following distractor offset and preceding target onset. Because the LRP is derived from negative deflections of the ERP over both cerebral hemispheres, a larger negative value of the LRP reflects larger relative activation of the hemisphere in control of the hand associated with the distractor-related response.

\section{Experiment 2}

Participants. Sixteen neurologically healthy students ( 6 female, 10 male, mean age 23.3 years, range 21-27 years old) of the Helmut-SchmidtUniversity/University of the Federal Armed Forces Hamburg gave informed consent to participate in this study in exchange for partial fulfillment of course requirements. None of them had participated in Experiment 1 . All had normal or corrected-to-normal vision according to self-report, and were naive with respect to the purpose of the experiment.

Apparatus, stimuli, and procedure. Hardware, software, stimuli, and procedure were identical to those in Experiment 1, with the following exceptions: First, we administered, in addition to the letter identification task used in Experiment 1, a new task, which involved Landolt rings as target and distractor stimuli. Landolt rings consisted of a circle with a small gap at $45^{\circ}$ (top right), $135^{\circ}$ (bottom right), $225^{\circ}$ (bottom left), or 
$315^{\circ}$ (top left). They were presented in black color and subtended a visual angle of $1.6^{\circ}$. Landolt rings were mapped to the response keys from left to right in the following order: gap at top-left position, gap at bottom-left position, gap at bottom-right position, and gap at topright position. (Because the inner response keys were nearer to the participant, this assignment yielded spatial correspondence between gaps and response keys.) Second, a neutral distractor-the letter $\mathrm{X}$ in the letter task and a complete ring in the Landolt ring task-which was unrelated to all four possible responses and never occurred as a target, was used in a proportion of trials in both high-utility and lowutility blocks. The congruent/incongruent/ neutral probability ratio was $0.75 / 0.10 / 0.15$ in high-utility blocks and $0.10 / 0.75 / 0.15$ in lowutility blocks (i.e., the neutral distractors replaced a proportion of congruent distractors in low-utility blocks and a proportion of incongruent distractors in high-utility blocks). Because in preliminary analyses the two versions of Experiment 2 did not substantially differ in any relevant aspect regarding our research questions, the data from the two versions were combined for further analyses.

Procedure. The procedure of Experiment 2 was identical to Experiment 1 with the exception that each participant took part in two different sessions (separated by 1-23 d, mean $9 \mathrm{~d}$ ), one involving letter stimuli and one involving Landolt ring stimuli. The assignment of stimulus material to session was counterbalanced across participants.

EEG recording. Identical to Experiment 1.

Statistical analyses. Identical to Experiment 1, with the exception that the N1 amplitude analyses were conducted for non-neutral trials and neutral trials separately. The peak latency of $\mathrm{N} 1$ for non-neutral distractors and neutral distractors were at 192 and $188 \mathrm{~ms}$ after distractor onset, respectively. For trials with nonneutral distractors, data from, on average, 622 $(\mathrm{SD}=144)$ and $486(\mathrm{SD}=89)$ epochs per participant were used for further analyses, for high-utility blocks and low-utility blocks, respectively. For trials with neutral distractors, data from, on average, $123(\mathrm{SD}=29)$ and 124 $(\mathrm{SD}=24)$ epochs per participant, for highutility blocks and low-utility blocks, respectively, were used for further analyses.

To increase the statistical power, the LRP analysis was run on the combined data from both experiments. (Because neutral distractors were not associated with any of the response hands the LRP analysis was confined to trials involving a non-neutral distractor.)

\section{Results}

\section{Behavioral data}

Median RTs and mean error proportions were subjected to ANOVAs with repeated measures on the factors utility condition (high-utility and low-utility) and congruency (congruent and incongruent; data from the neutral trials in Experiment 2 were not included in the analyses). A proportion congruency effect was obtained in both experiments (Fig. 1b). That is, comparing blocks of high and low utility, the congruency effect was reduced from 245 to $130 \mathrm{~ms}$ in RTs and from 7.1 to $0.8 \%$ in error percentages in

b distractor utility condition.
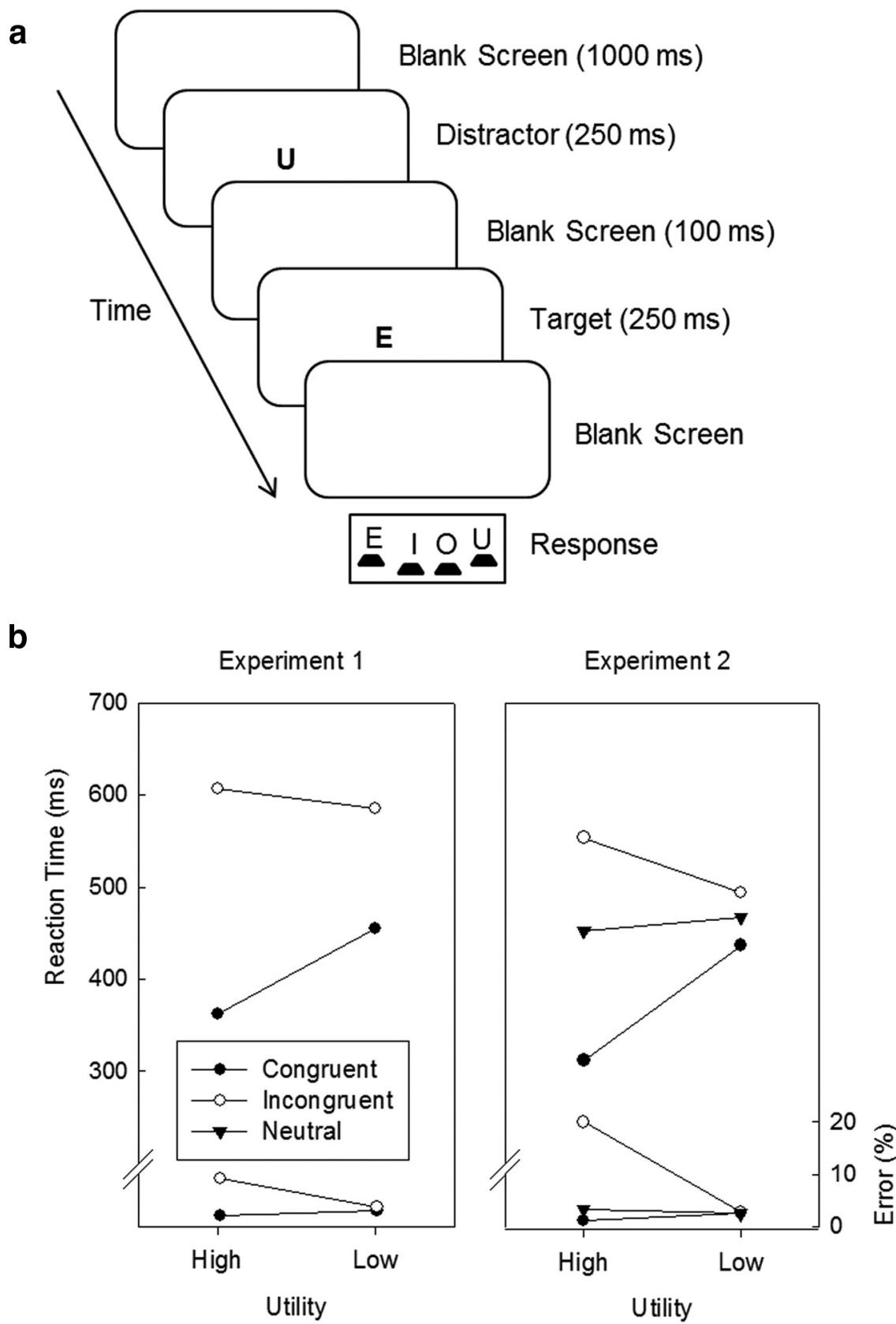

Figure 1. $\boldsymbol{a}$, Schematic of a (incongruent) trial involving the successive presentation of a distractor letter and a target letter. $\boldsymbol{b}$, Mean reaction times and error percentages in Experiments 1 and 2 as a function of the congruency level of the current trial and the

Experiment $1\left(F_{(1,15)}=60.9, p<0.001\right.$, and $F_{(1,15)}=5.8, p<0.03$, respectively), and from 242 to $57 \mathrm{~ms}$ in RTs and from 18.8 to $0.2 \%$ in error percentages in Experiment $2\left(F_{(1,15)}=179.1, p<\right.$ 0.001 , and $F_{(1,15)}=49.2, p<0.001$, respectively). In both experiments responding was overall slower in low-utility than in highutility blocks $\left(F_{(1,15)}=8.5, p<0.02\right.$, and $F_{(1,15)}=8.4, p<0.02$, in Experiments 1 and 2, respectively), but this was entirely driven by the congruent trials. Also, responses were less error prone in low-utility than in high-utility blocks $\left(F_{(1,15)}=4.7, p<0.05\right.$, and $F_{(1,15)}=31.0, p<0.01$, in Experiments 1 and 2, respectively), and this was entirely driven by the incongruent trials. This pattern of results suggests that participants adopted a more conservative response criterion in the low-utility blocks than in the highutility blocks, in addition to the adjustment concerning atten- 
a

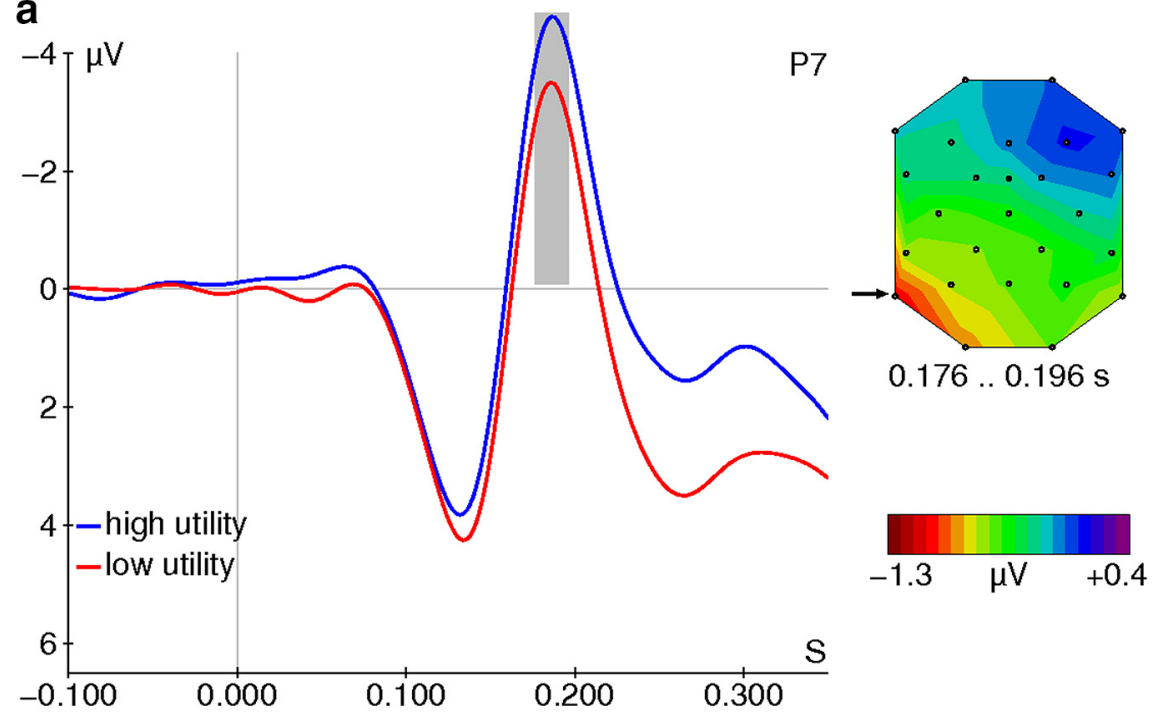

b

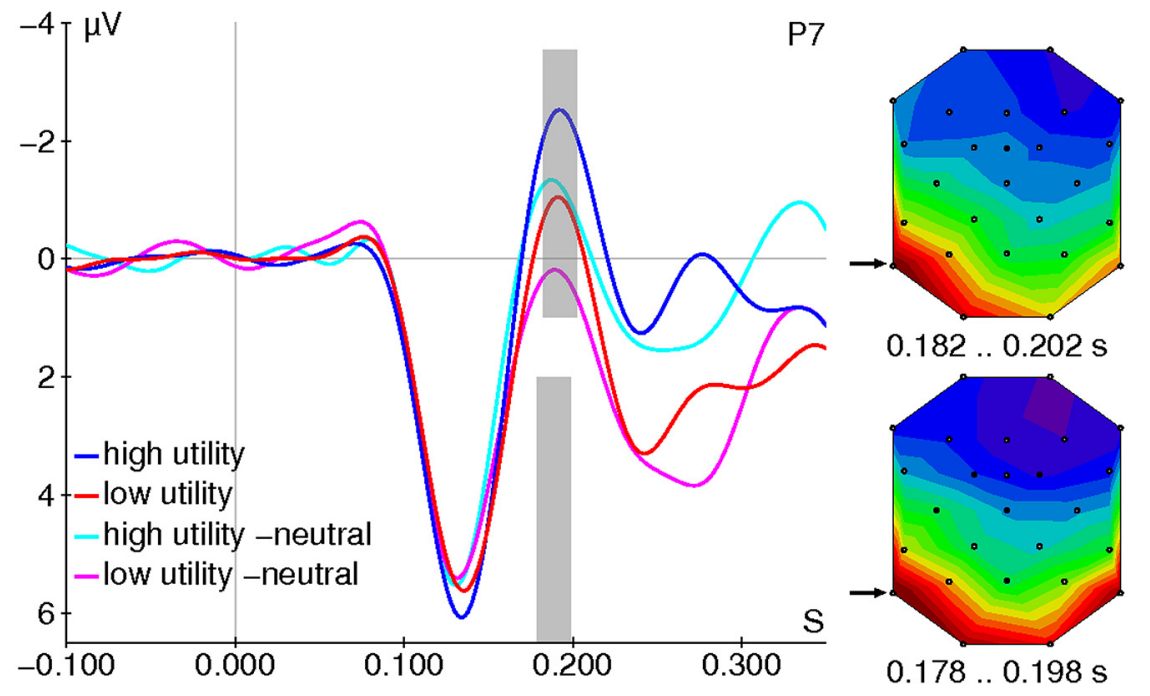

Figure 2. $\quad \boldsymbol{a}$, Grand average target-locked ERP at electrode site P7 during the distractor-target interval as a function of overall distractor utility and topography of the utility-related contrast in Experiment 1. $\boldsymbol{b}$, Grand average target-locked ERP at electrode site P7 during the distractor-target interval as a function of overall distractor utility and type of distractor as well as topographies of the utility-related contrasts in Experiment 2 (top map: non-neutral distractors, bottom map: neutral distractors). Black arrows indicate location of electrode site P7. Vertical gray lines indicate distractor onset. Gray areas indicate time windows used for calculation of N1 amplitudes evoked by non-neutral and neutral distractors (displayed at the same height as the respective topography map) in high-utility versus low-utility blocks.

tional selection. Using a four-alternative forced-choice task allowed us to classify errors in incongruent trials as distractor related (i.e., responses associated with the current distractor character) versus distractor unrelated (i.e., responses not associated with the current distractor character). Distractor-related errors were less frequent in low-utility blocks than in high-utility blocks (i.e., 1.6 vs $7.8 \%$ and 1.4 vs 19.1\%, in Experiments 1 and 2, respectively), whereas distractor-unrelated errors were overall rare and occurred with virtually equal frequency in low-utility and high-utility blocks (i.e., 0.2 vs $0.2 \%$ and 1.5 vs $1.5 \%$ in Experiments 1 and 2, respectively).

\section{ERP data}

For Experiment 1, the ANOVA yielded a marginally significant main effect for the utility condition $\left(F_{(1,15)}=3.8, p=0.07\right)$, qualified by a marginally significant twoway interaction with anterior-posterior electrode site $\left(F_{(3,45)}=2.5, p=0.07\right)$. There was no two-way interaction of utility and left-right electrode site $\left(F_{(1,15)}=\right.$ $1.8, p=0.20)$, and no three-way interaction $\left(F_{(3,45)}=1.0, p=0.39\right)$. Planned comparisons showed that the utility effect was significant for electrodes of the P-line and marginally significant for electrodes of the O-line (averaged across left and right electrode sites; $F_{(1,15)}=5.6, p<$ 0.05 , and $F_{(1,15)}=4.2, p=0.06$, respectively), but not for electrodes of the F-line or of the C-line $\left(F<1\right.$, and $F_{(1,15)}=2.7$, $p=0.12$, respectively). Fig. $2 a$ presents the waveforms at electrode P7 and the topographies of the utility-related contrast.

The pattern of results was similar for Experiment 2 (Fig. 2b). Precisely, for nonneutral trials the ANOVA yielded a significant main effect of the utility condition $\left(F_{(1,15)}=5.0, p<0.05\right)$, modulated by a two-way interaction with anterior-posterior electrode site $\left(F_{(3,45)}=5.6, p<0.01\right)$. Unlike in Experiment 1, however, there was also a two-way interaction of utility condition and left-right electrode site $\left(F_{(1,15)}=7.5, p<0.02\right)$, reflecting that the utility effect was generally larger at leftsided than at right-sided electrode sites. Again, there was no three-way interaction $\left(F_{(3,45)}<1\right)$. Planned comparisons showed that the utility effect was significant for electrodes of the P-line and for electrodes of the O-line (averaged across left and right electrode sites; $F_{(1,15)}=8.0$, $p<0.05$, and $F_{(1,15)}=6.90, p<0.05$, respectively), but not for electrodes of the F-line or of the C-line (both $F$ s $<1$ ).

For neutral trials, the main effect of utility condition did not reach significance $\left(F_{(1,15)}=1.5, p=0.24\right)$. However, there was again a two-way interaction with anterior-posterior electrode site $\left(F_{(3,45)}=10.0, p<0.01\right)$. In contrast, there was no two-way interaction of utility and left-right electrode site, and no threeway interaction (both $F$ s $<1$ ). Planned comparisons showed that the utility effect was significant for electrodes of the P-line and marginally significant for electrodes of the O-line (averaged across left and right electrode sites; $F_{(1,15)}$ $=6.6, p<0.05$, and $F_{(1,15)}=4.2, p=0.06$, respectively), but not for electrodes of the F-line or of the C-line (both Fs $<1$ ).

The LRP was larger in high-utility than in low-utility conditions $\left(F_{(1,30)}=6.2, p<0.02\right)$. This did not differ between the experiments $\left(F_{(1,30)}<1\right)$. Figure 3 displays the LRPs in highutility and low-utility blocks during the distractor-to-target intervals.

\section{Discussion}

Previous studies on strategic adjustment of distractor processing have been inconclusive regarding two important questions. First, 
it has remained unclear whether distractor utility-related adjustment is brought about by modulating the processing of target rather than distractor information (some models assuming both; Botvinick et al., 2001). Second, previous ERP studies investigating the proportion congruency effect (Bartholow et al., 2005; Bartholow and Dickter, 2008; Purmann et al., 2011; Tillman and Wiens, 2011) could not determine whether the adjustment affects early stages of processing. Here, we manipulated distractor utility in a Temporal Flanker Task and recorded distractorrelated ERPs before target presentation. With this method, the only physical feature discriminating targets and distractors was the time of onset. Early adjustment of distractor processing may thus be brought about by variations in readiness for stimulus processing at the time of distractor presentation. Indeed, explicit cuing of stimulus onset has been shown to affect early perceptual stages by findings of larger stimulusevoked ERPs (i.e., posterior P1 or N1 amplitude) in valid than in invalid cuing conditions (Correa et al., 2006).

The behavioral results of our experiments replicated previous findings. Distractor interference was larger in conditions associated with higher distractor utility. Concerning ERPs, in both experiments, a larger amplitude of the distractor-elicited posterior N1 was observed in high-utility than in low-utility conditions, demonstrating adjustment of distractor processing during relatively early perceptual stages. Contrasting with the non-neutral distractors, the neutral distractors in Experiment 2 were randomly paired with all possible targets/responses across both utility conditions. Still, qualitatively the same modulation of the posterior N1 was observed for neutral as for non-neutral distractors, demonstrating that the utility adjustment is not bound to individual stimuli that have been strongly linked to a particular response, but may apply to a wider range of stimuli associated with the distractor-defining feature.

Given that high-utility and low-utility blocks can be assumed to be associated with different frequencies of conflict between response codes, our findings accord well with prominent models assuming adjustments of processing targets and distractors based on monitoring of response conflict (Botvinick et al., 2001). Because our congruent condition was made up of pairs of identical stimulus items, however, it cannot be dismissed that expectations regarding specific perceptual features of the upcoming target are a crucial factor for the observed adjustment.

The posterior N1 has been linked to processes of stimulus discrimination in choice tasks (Vogel and Luck, 2000; Hopf et al., 2002). In particular, its amplitude is augmented in situations of increased discrimination difficulty (Fedota et al., 2012). A straightforward account of the modulation found in our experi-

b
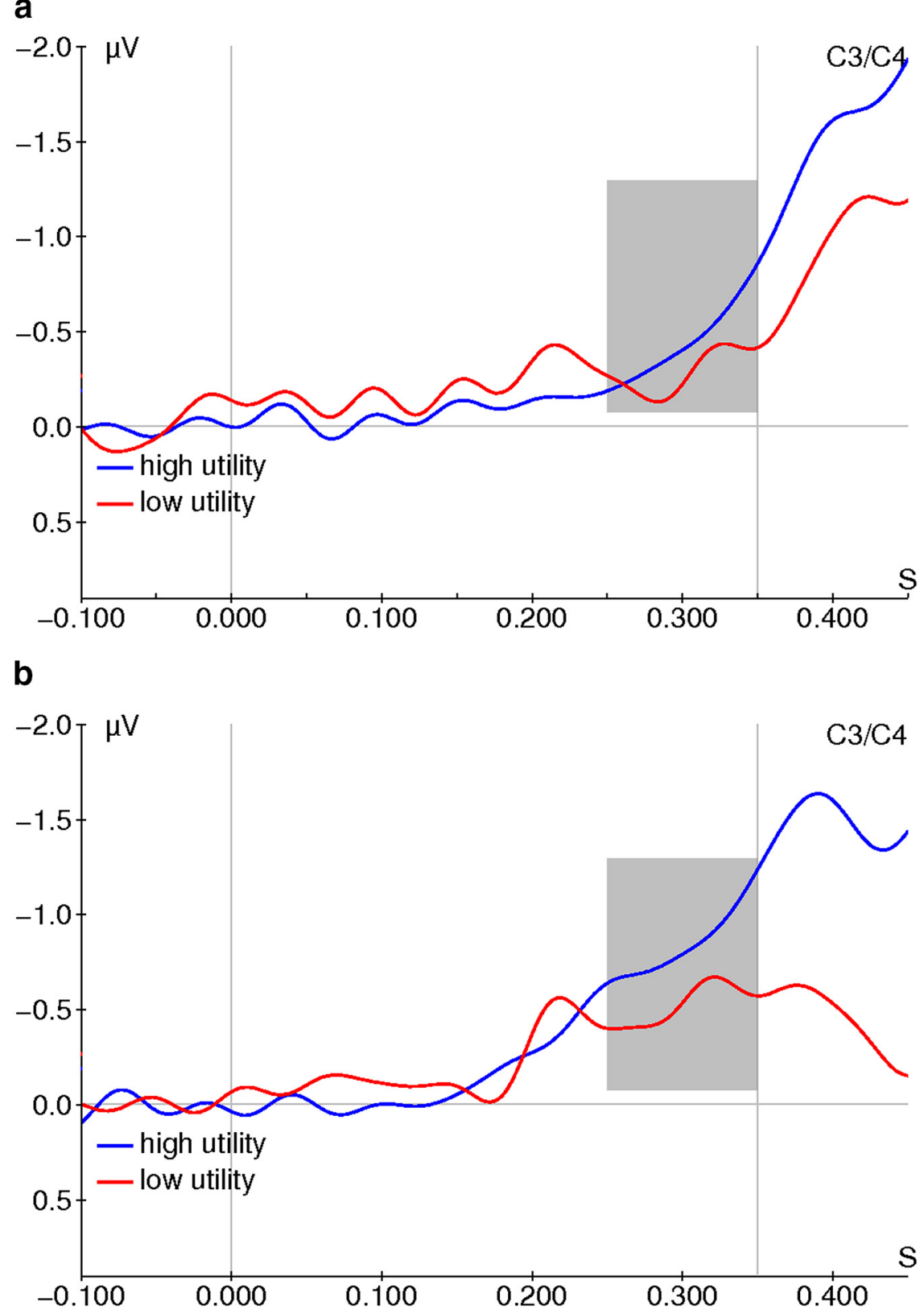

S

Figure 3. Effect of the utility condition on the LRP during the distractor-target interval in Experiment $1(\boldsymbol{a})$ and Experiment $2(\boldsymbol{b})$. Vertical gray lines indicate distractor and target onset. Gray areas indicate time windows used for calculation of LRP amplitudes.

ments is thus to assume distractor utility-based regulation of stimulus identification or categorization processes, possibly resulting in increased "depth" of encoding discriminative features of the distractor items in high-utility conditions. In addition to these perceptual alterations, (non-neutral) distractors in highutility conditions also seemed to elicit more pronounced activation of their associated responses. Specifically, we observed a larger bias favoring the hemisphere in control of the hand associated with the distractor-related response when comparing distractor-elicited potentials obtained from electrodes over the left and right motor cortices (i.e., LRP; Eimer, 1998) as well as a substantially higher frequency of distractor-related response errors but not distractor-unrelated response errors in high-utility than in low-utility conditions.

Clearly, findings of processing adjustment occurring in early perceptual stages do not preclude the possibility of additional 
adjustment mechanisms that come into play during later stages of processing (i.e., after some degree of stimulus identification has been completed or after sensory information has been transformed into a more abstract code; Wendt et al., 2013). Distractor utility-based processing adjustment may thus involve a variety of mechanisms, and the application of a specific mechanism may depend on the precise task requirements and context conditions. The current study provides evidence for the assumption that utility-dependent weighting of distractor information during early processing stages is one of these mechanisms.

\section{References}

Bartholow BD, Dickter CL (2008) A response conflict account of the effects of stereotypes on racial categorization. Soc Cognition 26:314-332. CrossRef

Bartholow BD, Pearson MA, Dickter CL, Sher KJ, Fabiani M, Gratton G (2005) Strategic control and medial frontal negativity: beyond errors and response conflict. Psychophysiology 42:33-42. CrossRef Medline

Botvinick MM, Braver TS, Barch DM, Carter CS, Cohen JD (2001) Conflict monitoring and cognitive control. Psychol Rev 108:624-652. CrossRef Medline

Correa A, Lupiáñez J, Madrid E, Tudela P (2006) Temporal attention enhances early visual processing: a review and new evidence from eventrelated potentials. Brain Res 1076:116-128. CrossRef Medline

Crump MJ, Milliken B (2009) The flexibility of context-specific control: evidence for context-driven generalization of item-specific control settings. Q J Exp Psychol 62:1523-1532. CrossRef Medline

Egner T, Hirsch J (2005) Cognitive control mechanisms resolve conflict through cortical amplification of task-relevant information. Nat Neurosci 8:1784-1790. CrossRef Medline

Eimer M (1998) The lateralized readiness potential as an on-line measure of selective response activation. Behav Res Methods Instrum Comput 30: 146-156. CrossRef

Eriksen BA, Eriksen CW (1974) Effects of noise letters upon the identification of a target letter in a nonsearch task. Percept Psychophys 16:143-149. CrossRef

Fedota JR, McDonald CG, Roberts DM, Parasuraman R (2012) Contextual task difficulty modulates stimulus discrimination: electrophysiological evidence for interaction between sensory and executive processes. Psychophysiology 49:1384-1393. CrossRef Medline

Gratton G, Coles MG, Donchin E (1992) Optimizing the use of information: strategic control of activation of responses. J Exp Psychol Gen 121: 480-506. CrossRef Medline

Hazeltine E, Lightman E, Schwarb H, Schumacher EH (2011) The boundaries of sequential modulations: evidence for set-level control. J Exp Psychol Hum Percept Perform 37:1898-1914. CrossRef Medline

Hillyard SA, Anllo-Vento L (1998) Event-related brain potentials in the study of visual selective attention. Proc Natl Acad Sci U S A 95:781-787. CrossRef Medline

Hillyard SA, Vogel EK, Luck SJ (1998) Sensory gain (amplification) as a mechanism of selective attention: electrophysiological and neuroimaging evidence. Philos Trans R Soc Lond B Biol Sci 353:1257-1270. CrossRef Medline

Hopf JM, Vogel E, Woodman G, Heinze HJ, Luck SJ (2002) Localizing visual discrimination processes in time and space. J Neurophysiol 88:2088 2095. Medline

Logan GD, Zbrodoff NJ (1979) When it helps to be misled: facilitative effects of increasing the frequency of conflicting stimuli in Stroop-like tasks. Mem Cogn 7:166-174. CrossRef

Melara RD, Algom D (2003) Driven by information: a tectonic theory of Stroop effects. Psychol Rev 110:422-471. CrossRef Medline

Purmann S, Badde S, Luna-Rodriguez A, Wendt M (2011) Adaptation to frequent conflict in the Eriksen flanker task: an ERP study. J Psychophysiol 25:50-59. CrossRef

Stroop JRJ (1935) Studies of interference in serial verbal reactions. J Exp Psychol 18:643-662. CrossRef

Tillman CM, Wiens S (2011) Behavioral and ERP indices of response conflict in Stroop and flanker tasks. Psychophysiology 48:1405-1411. CrossRef Medline

Vogel EK, Luck SJ (2000) The visual N1 component as an index of a discrimination process. Psychophysiology 37:190-203. CrossRef Medline

Wendt M, Luna-Rodriguez A, Jacobsen T (2012) Conflict-induced perceptual filtering. J Exp Psychol Hum Percept Perform 38:675-686. CrossRef Medline

Wendt M, Luna-Rodriguez A, Kiesel A, Jacobsen T (2013) Conflict adjustment devoid of perceptual selection. Acta Psychol 144:31-39. CrossRef Medline 